\title{
The role of eye movements in the perception of visually induced motion
}

\author{
LEONARD BRDSGOLE, ST, JOHN'S UNIVERSITY; ROBERT M. CRISTAL, SOUTHAMPTON COLLEGE \\ OTIS CARPENTER, MEMORIAL SLOAN KETTERING
}

Changes in eye position were recorded while $S$ experienced visually induced motion. Movement of the eye was not found to correlate, in either direction or extent, with this type of apparent motion. Induced movement was explained, therefore, in terms of a change in phenomenal rather than retinal location.

When an objectively stationary and fixated stimulus is placed within the context of a laterally displacing frame, the target is seen to move in a direction opposite to the true motion of the frame. Meanwhile, the frame, or surround, seems to remain fairly fixed in space. Duncher (1929) called this phenomenon "induced motion."

Brosgole (1966) attempted to explain the induced effect in terms of a change in the egocentric location of the target. He found that the subjective straight ahead tended to be localized near the center of the visual surround (Roelofs' effect). Furthermore, as the background displaced back and forth in space, the apparent median plane shifted along with it so as to remain symmetrically located within the visual field. The objectively stationary and fixated target, then, was seen to move because it continuously changed position with regard to the phenomenally straight ahead location.

It could be argued that although Ss are usually instructed to gaze directly at the enclosed stimulus object, there is nevertheless a tendency for the eye involuntarily to pursue the laterally displacing background. Such an unmonitored shift in eye position would naturally give rise to a change in the retinal location of the stimulus and, hence, the experience of target movement. Thus, the purely descriptive or phenomenological explanation offered above could be reduced to a more fundamental physiological level.

The purpose of the following experiment was to determine whether visually induced motion is based upon changes in eye position or shifts in the egocentric location of the target.

\section{METHOD}

The logic of this study demanded a piece of apparatus for generating induced motion and recording the amount of apparent target movement, as well as equipment for plotting the precise position of the eye. Each will be described separately in the immediately following sections.

\section{Induced motion apparafus}

The induced motion device has been fully described elsewhere (Brosgole, 1967). It basically consisted of a frame, 60 in. high $x 30$ in. wide, upon which stimuli could be mounted. It was remotely driven back and forth along a set of tracks by a variable speed motor. It traveled 22 in. across space, 11 in. to the right and left of the objective median plane, at a rate of $20^{\circ}$ of visual arc per sec. At the end of its 22 in. journey, the screen activated a relay reversing the motor and, thereby, its direction of travel. As its total excursion was $10020^{\circ}$, it displaced in a given direction for $31 \mathrm{sec}$ before reversing. The inducing stimuli were fastened to the screen.

The $S$ controlled a target located directly in front of the screen at eye level. He was able to move it $30 \mathrm{in}$. to the right and left of the objective median plane by rotating a knob affixed to the shaft of a Selsyns synchronous motor. The position of the target and screen was automatically plotted on a Brush strip chart recorder.

\section{Stimuli}

The stimuli consisted of a $3 / 8 \mathrm{in.} \mathrm{diameter} \mathrm{cir-}$ cular spot of light surrounded by a $24 \times 30$ in. horizontal rectangular frame with $1-1 / 8$ in. wide borders. The circular target was under S's control while the frame was attached to the screen varied by $E$. They were both constructed of Sylvania white, electroluminescent Tape-Lite. Their brightness was regulated with the target set at 1.8 and the frame at $.009 \mathrm{ft}-\mathrm{L}$.

\section{Biopotential Recording System}

The horizontal position of the eye was ascertained by monitoring discrete changes in the corneo-retinal potential. A pair of Beckman skin electrodes, filled with sodium chloride gel, was applied to the temples of $S$ immediately adjacent to the lateral canthus of each eye. The potential difference between the cornea of one eye and the retina of the other passed through two stages of dc amplification, from a Brush high gain differential amplifier (RD 4215-60) through a Brush medium gain amplifier (RD 5615 11) to the above mentioned strip chart recorder which operated at a paper speed of $1 \mathrm{~mm} / \mathrm{sec}$.

Common mode rejection aided in the elimination of noise along with the use of low pass filters. The signal peaked at $0.25 \mathrm{cps}$ and was $3 \mathrm{~dB}$ down at 1.0 cps. Such extensive filtering was of no consequence, because we were primarily concerned with the more persistent changes in eye position, i.e., those which 
indicated that the slowly displacing surround was being pursued. The availability of a true earth ground facilitated even a further reduction of noise. Zero suppression was added to counteract large offset voltages, as well as long term drift.

This particular recording system was found to be linear within $40^{\circ}$ of eye rotation with a capacity to accurately resolve as little as $1 / 4^{\circ}$ of movement. The equipment was calibrated for each $\mathrm{S}$, by the use of perimetry, prior to the experimental session. This procedure was monitored on a Tektronix oscilloscope (Model No. 545A with a Type D plug-in unit) which was tied into the system in parallel.

\section{Procedure}

The experiment took place in a totally darkened room with the recording equipment located in an adjoining control room. The two were linked together by a voice communication system. The electrode leads passed from $S$ through a network of light locks into the control booth.

A stabilization period of $15 \mathrm{~min}$ was allowed to elapse after placement of the electrodes. This was followed by the aforementioned calibration procedure. DC drift was monitored over the next $45 \mathrm{~min}$. All Ss demonstrating more than a $10 \mu \mathrm{V}$ drift over the last half hour period were immediately rejected. Additional Ss were dropped whenever there was evidence of an offset problem, i.e., when a return of the eyes to a central fixation point failed to produce a concomitant return to base line on the scope and recorder. The equipment was then calibrated for each of the remaining $S s$ and the experiment.commençed.

The $\mathrm{S}$ sat $10 \mathrm{ft}$ in front of the induced motion apparatus with his head positioned in a Bausch and Lomb head and chin rest. The chin rest.was adjusted so that the circular target was at eye level.

The study consisted of three conditions. The first was aimed at ascertaining precisely how much motion the displacing surround tended to induce in the target. With the center of the frame and target set in S's objective median plane, $S$ was directed to fixate the target and ignore the frame at all times. He was told that $\mathrm{E}$ could independently control the motion of both the target and frame so that one could be seen as moving and the other stationary, or both could move simultaneously in the same or opposite directions. (Of course, $\mathrm{E}$ was able to manipulate the frame.) S was further advised that he, too, could control the motion of the target by turning the control knob appropriately. His task was to cancel-out whatever motion $E$ might impose upon the target so as to hold it frozen in space or perfectly stationary. Accordingly, an apparent leftward movement of the target yielded an adjustment to the right and vice versa. Thus, the amount of induced movement was gauged through such a compensatory tracking procedure. After $S$ demonstrated an understanding of the in- structions, the surround was set into motion. In half the cases it displaced from center to the right by 11 in., back through center to the left by 11 in., and back to center again for five such cycles or trials. In the other half, its initial motion was to the left. S's adjustments were recorded as the surround shifted back and forth at the previously specified rate.

The second condition was identical to the first except that $S$ was no longer permitted to adjust the target. His sole task was to fixate upon it, ignoring the laterally displacing frame at all times. Therefore, the target remained perfectly stationary in the objective median plane. This enabled us to determine whether or not the frame generated changes in eye position which correlated with the apparent movement of the target in both direction and magnitude.

The third condition was directed at disclosing whether or not the displacing surround effected shifts in the apparent median plane and if these were, in fact, related to the phenomenal movement of the target. Therefore, the target was occluded with $S$ instructed to gaze directly straight ahead, ignoring the frame at all times. Thus, changes in the subjective straight ahead were obtained using the eye as a pointing instrument. The order of the three conditions was counterbalanced over Ss.

\section{Subjects}

Five males and one female participated in this study. 1 Ranging in age from 18-37, their mean age was 24.7 years. They were undergraduate students who were naive as to the purpose of this experiment.

\section{RESULTS AND DISCUSSION}

In Condition $1, S^{\prime} s$ setting of the target was noted when the frame was at its extreme right and left positions. The difference between these settings represented the range of motion induced in the target for a given cycle or trial. The mean range was calculated for each $S$ over five trials. Averaging across $\mathrm{Ss}$, the target was induced to move $2.62^{\circ}$. Its apparent movement was always in a direction opposite to the true motion of the surround.

A range of eye movements was similarly derived for the second and third conditions, i.e., the position of the eye was noted when the frame was at its extremes. These differences in the direction of $S^{\prime} s$ gaze were averaged across trials and then over Ss. There was some tendency to pursue the frame in Condition 2, but only by $0.09^{\circ}$. Such breaks in fixation were noted in only four of the six cases. The remaining two $S$ tended to break from the target in a direction opposite to the frame.

In Condition 3 the subjective straight ahead shifted along with the center of the laterally displacing frame by $2.76^{\circ}$. This was apparent in every case. 2

The differences between conditions were significant 
according to the Friedman two-way analysis of variance $\left(\mathrm{Xr}^{2}=9, \mathrm{p}<.01\right)$. The binomial test indicated, however, that while Conditions 1 and 3 were essentially the same, they both differed reliably from Condition 2 ( $p<.02$ in each instance).

These findings indicate that induced motion is thoroughly unrelated to a systematic shift in the retinal location of the enclosed stimulus. Rather, it appears to be based upon an egocentrically determined position change in phenomenal space.

\section{References}

Brosgole, L. An analysis of induced motion. Port Washington: Naval Training Device Center, Tech.Rep. IH-48, February, 1966.
Brosgole, L. Induced autokinesis. Percept. \& Psychophys., 1967, 2, 69-73.

Duncker, K. Über induzierte Bewegung (Ein Beitrag zur Theorie Optisch Wahrgenommener). Psychol. Forsch., 1929, 12, 180-259.

\section{Notes}

1. Approximately two dozen additional ss were rejected because of our rigid criteria.

2. It is interesting to note that the Ss felt as if their eyes were perfectly stationary, even though they were objectively pursuing the laterally displacing frame. On the other hand, they felt as if they were actively following the apparently moving target, in Condition 2, despite the fact that they were fixating directly upon it. These reports serve to indicate that phenomenal and objective eye position need not coincide.

(Accepted for publication October $21,1967$. 